\title{
Global Warming and the Physiology of Ectothermic Animals: The Case of Three Mexican Lizards
}

\author{
Fajardo V1*, Gonzalez Morales JC1,2, Rivera-Rea J1 and Bastiaans E ${ }^{3}$ \\ ${ }^{1}$ Autonomous University of the State of Mexico, Mexico \\ ${ }^{2}$ Autonomous University of Tlaxcala, Mexico \\ ${ }^{3}$ Department of Biology, State University of New York College at Oneonta, USA
}

\section{Mini Review}

Volume 2 Issue 6

Received Date: December 06, 2019

Published Date: December 30, 2019

DOI: $10.23880 /$ izab-16000195

*Corresponding author: Victor Fajardo, Autonomous University of the State of

Mexico, Institute for the Conservation of the Neovolcanic Mountain Range in the face of Climate Change. Lake Atitlán No. 502B, Colonia Nueva Oxtotitlán, Toluca, State of Mexico. C.P. 50100, Mexico, Email: fajardo.vic@gmail.com

\section{Abstract}

Global warming has a direct impact on the geographic distribution and abundance of reptiles, and it can even lead to their extinction. Theoretical models project that many lizards could migrate along an altitudinal gradient, however, this prediction does not take into account lack of oxygen or hypoxia as a constraint factor for migration. We discuss possible morpho physiological traits that could affect whether ectotherms can migrate from lower to higher altitudes, despite the potential negative effects of hypoxia. It is fundamental that climate change research considers the vulnerability of ectotherms facing global warming, not only in terms of their thermal biology, but also considering their physiology.

Keywords: Global Warming; Lizards; Hypoxia; Hematology Traits

\section{Global Warming and Ectotherms}

NOAA (National Oceanic and Atmospheric Administration) data have served as the basis for innumerable scientific studies demonstrating a gradual increase in the average temperature of the planet [1-3], (Figure 1). This increase is of almost $0.5^{\circ} \mathrm{C}$ if we take as a starting point the average temperature recorded between the years 1961 to 1990 , and of almost $1^{\circ} \mathrm{C}$ if we compare it with the second half of the 19th century, that is, between 1850 and 1900 [4]. Global warming is related to an increase in atmospheric $\mathrm{CO}_{2}$, which is a strong indicator that one of the main causes of the environmental warming is the intensification of the greenhouse effect [4].
Global warming is also detectable locally; in Figure 2 we show a graph made with data obtained from the meteorological station of Tenango del Valle, State of Mexico (19 $06^{\prime} 09^{\prime \prime} \mathrm{N}$ and $99^{\circ} 35^{\prime} 20^{\prime \prime} \mathrm{W}$ ), where we clearly observe an increase in air temperature, especially during the early 1990s. Although relatively low temperatures are observed in the $80 \mathrm{~s}$ and $90 \mathrm{~s}$, the tendency to raise environmental temperatures is irrefutable. Furthermore, the latest report issued by the United Nations Intergovernmental Panel on Climate Change (IPCC) concludes that we are close to passing the crucial threshold of $1.5^{\circ} \mathrm{C}$ above pre-industrial temperature levels, which would substantially alter many of Earth's ecosystems desertification and would increase droughts, wildfires, and floods [5]. 


\section{International Journal of Zoology and Animal Biology}

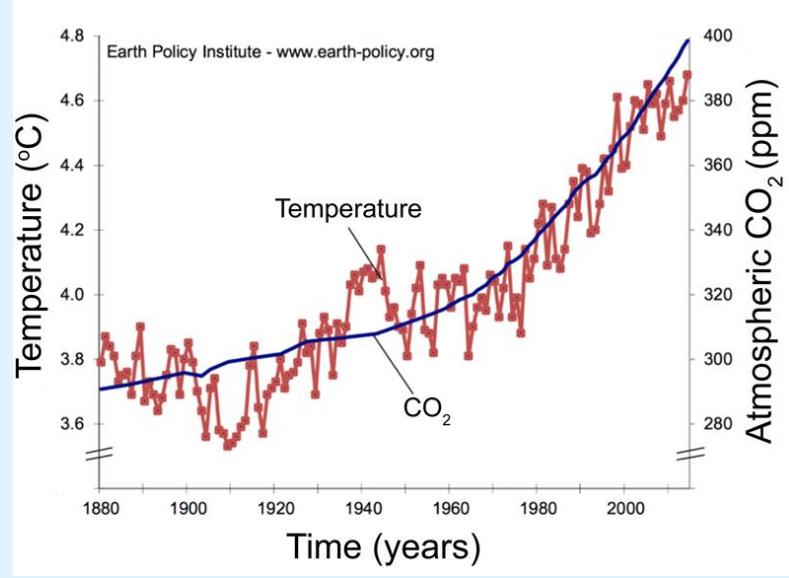

Figure 1: Temperature and $\mathrm{CO}_{2}$ over the years, note the increase in both parameters. Source: Original creation based on NOAA data.

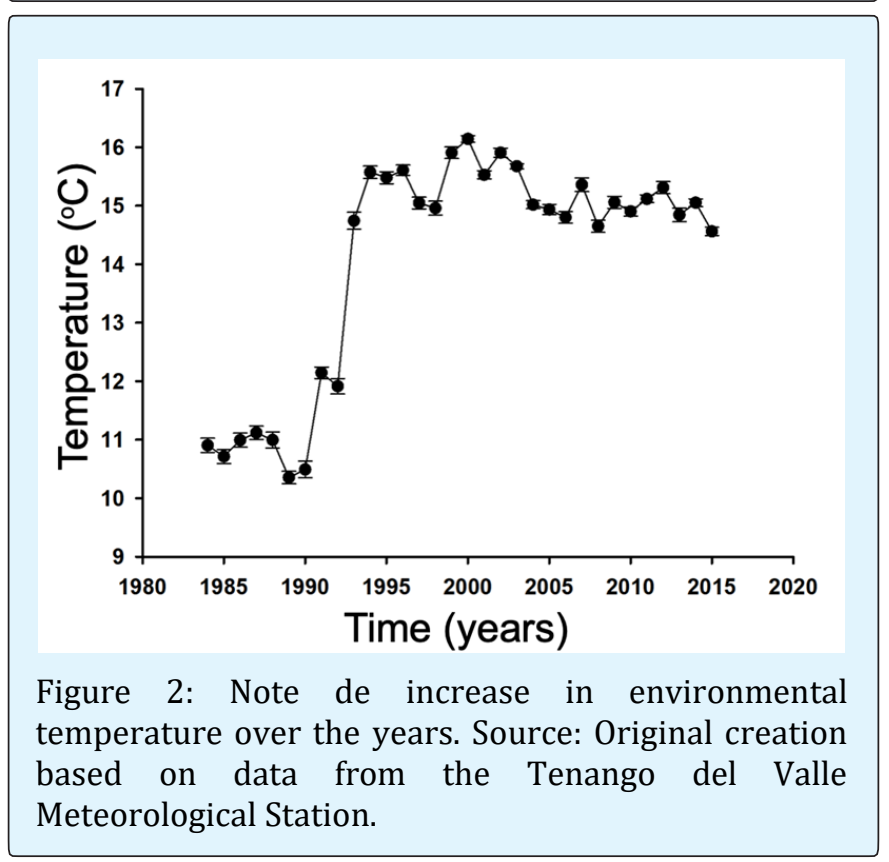

In addition to this, several studies have speculated that global warming will cause the extinction of species as well as changes in their spatial distribution, although there are few data that validate such predictions $[6,7]$. Particularly, in the case of non-avian reptiles such as lizards, global warming is a very powerful selective force. From a metabolic point of view, animals can be classified into two large groups, endotherms and ectotherms, according to the way they produce and maintain their body temperature. Three major traits differ between these groups: 1: Ectotherms (including lizards and other non-avian reptiles) acquire their body heat through exposure to environmental heat sources. In contrast, endotherms produce their body heat through metabolic processes that involve transforming the food they ingest into heat, which implies higher trophic costs. 2: When the environmental temperature decreases, ectotherms lower their body temperature and their metabolism. For example, during the night, ectotherms use only a third of the energy they use during the day; however, for most endotherms the decrease in temperature at night plays an inverse role, because they must increase their metabolism to maintain a constant body temperature. 3: The need to maintain body temperature causes an endothermic organism to spend more time foraging to acquire enough food to maintain its body temperature. In contrast, ectotherms invest a less time in foraging and need a smaller amount of food per unit body mass, freeing them to spend extra time on reproduction and invest a greater proportion of their resources in fecundity $[8,9]$.

Although ectothermic organisms have several advantages over endotherms, there are important costs associated with ectothermic thermoregulation. The most prominent is the limitation imposed by environmental temperatures on ectotherms' latitudinal and altitudinal distributions. Ectotherms' dependence on ambient temperatures for body heat limits them to environments where the temperatures allow them to be active during at least part of the year. In contrast, the internal temperature regulation of endotherms allows them to inhabit environments where the ambient temperature is outside their active range for much of the year. This pattern explains the predominance of endotherms in ecosystems where the environmental temperature is extremely low throughout the year, such as the polar areas $[8,9]$.

Considering this information, various groups of herpetologists have begun to analyze the effect of global warming on reptile species $[6,7,10]$ and predict how they can cope. One idea that has been discussed in the literature is that reptiles could migrate along an altitudinal gradient, such as the mountains, to search for thermally adequate sites [6,7]. However, in addition to their lower temperatures compared to lower altitudes, higher altitudes have a lower amount of oxygen available, a phenomenon called hypoxia [11-14].

Because oxygen is essential for all animals, both endotherms and ectotherms must acclimate (via phenotypic plasticity) or adapt (as a result of natural selection) to environments with hypoxia. In ectotherms these acclimations and adaptations include a great variety 
of morphophysiological changes in the cardiovascular and respiratory system [15]. Possible strategies include increasing the transport of oxygen in the blood by increasing the number of erythrocytes, increasing hematocrit and hemoglobin concentrations, and increasing the area of erythrocytes. Not all ectotherms exhibit all these changes, but they have each been described in fish, frogs and lizards [11-14]. In addition, at lower oxygen, metabolic rates in ectothermic animals tend to be reduced [16].

\section{Lizards and Hypoxia}

Faced with a scenario of elevated temperatures associated with global warming, some ectothermic species may have the option of migrating to cooler environments at higher altitudes. However, this refuge is only available to species that can respond morphophysiologically or metabolically to hypoxia $[14,17,18]$. The mechanisms of phenotypic plasticity and/or adaptations for coping with hypoxia have been analyzed through population-level comparisons of several species of vertebrates living in high and low elevations. In these species, blood traits such as erythrocyte count, hematocrit percentage and hemoglobin concentration tend to change with altitude. However, the direction and details of these changes vary by taxon: for example, in mammals and birds (with few exceptions) the response to hypoxia is to increase the values of blood traits in a phenomenon called the blood response. In amphibians, in contrast, erythrocyte counts typically increase but their size decreases [12]. In the case of reptiles, it is difficult to establish a clear pattern based on existing data. For example, in our laboratory we have found that some lizards of the genus Sceloporus present a hematic response to hypoxia [14,18], but this response is not observed in individuals of Heloderma horridum [19].

In Mexico three lacertilians have been studied in detail: Sceloporus torquatus [14], Sceloporus grammicus [18] and Heloderma horridum [19]. Sceloporus torquatus is a saxicolous lizard [20], distributed in central Mexico. According to the Official Mexican Standard (NOM-059ECOL-2010) it is endemic to Mexico and is not subject to any special protection [21-23]. It has a snout-vent length of between 15 and 20 centimeters, and adult males show blue coloration in the gular region and in lateral patches, which makes it a very striking lizard for the illicit pet trade [24]. It has been studied because it has a wide range of altitudinal distribution (from 1450 to $3000 \mathrm{~m}$ altitude) and is abundant in moderately disturbed areas. This lizard exhibits a hypoxic blood response, increasing its blood values and thereby increasing its capacity to transport oxygen from the lungs to the tissues [14], (Figure 3). Wheaters, et al. [25], were the first to show that an ectotherm can respond to hypoxia, and with this knowledge it became feasible to predict an altitudinal migration of lizards in the future. However, it is still necessary to determine whether the thermal biology of these organisms could allow such migration $[26,27]$.

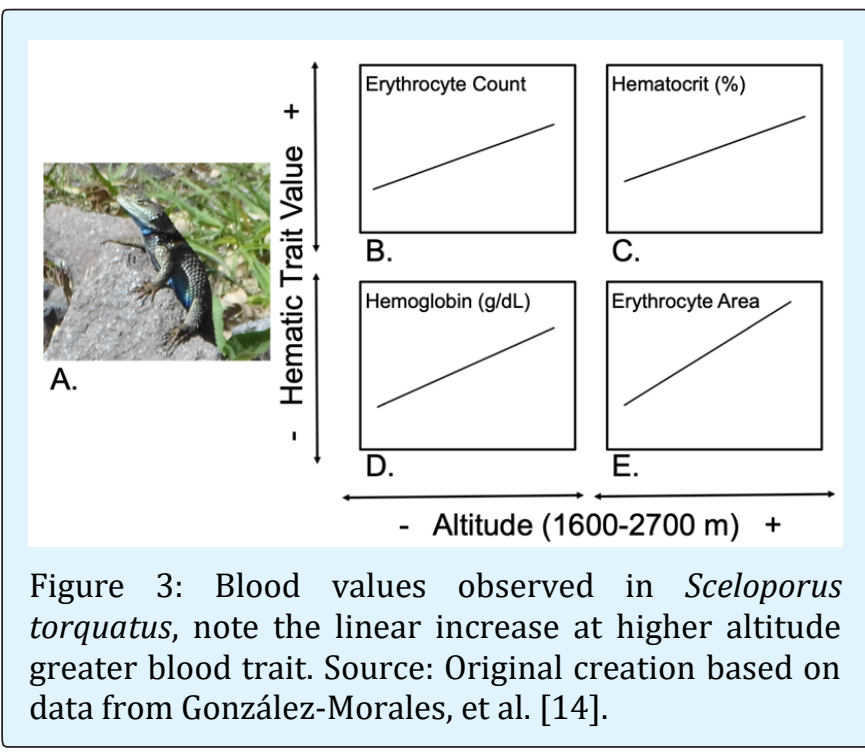

\section{Evolutionary Ecology of Thermoregulatory Behavior in Ectotherms}

Two main hypotheses have been proposed regarding the thermal biology of ectotherms in heterogeneous environments, such as altitudinal gradients: the first was proposed by Adolph, et al. [28] and suggests that thermal features should show adaptation to the environment; that is, they can be modified due to seasonality, latitude and altitude. Such is the case of the lizard Iberalocerta galani, in which the selected temperature (the temperature chosen by the animals under laboratory conditions) is high in spring and low in summer, with the aim of minimizing the costs of thermoregulation [29]. The second hypothesis proposes that thermal biology is evolutionarily conservative, that is, it is not modified by the effect of season, latitude or altitude, so behavioral adjustments are sufficient to mitigate environmental changes [30]. This hypothesis also has empirical support; for example, Sceloporus undulatus show similar selection temperatures in two populations from different altitudes [31].

For the genus Sceloporus in general, the current data are better suited to the evolutionary conservatism 


\section{International Journal of Zoology and Animal Biology}

hypothesis, because most studies have found that body temperature and activity do not vary with altitude or latitude [32]. This has led to the idea that thermoregulation in thermally unfavorable environments represents a very high cost, so lizards that live at extreme altitudes must compensate at various levels of biological organization to survive and reproduce in those places. However, studies documenting the existence and mechanism of this compensation are lacking [32].

The lizard Sceloporus torquatus can be considered as an eurythermic species, meaning that it has a wide range of selected temperatures, which in the laboratory range from 22.4 to $33.7^{\circ} \mathrm{C}$ [26]. These results suggest that $S$. torquatus may be able to migrate to higher altitudes and avoid the effects of global warming. We conducted another study using a higher-altitude lizard, Sceloporus grammicus, which is an arboreal lizard that is distributed in central Mexico. Its common name is mesquite lizard, it lives from $450 \mathrm{~m}$ to $4600 \mathrm{~m}$ altitude and according to the Official Mexican Standard NOM-059-ECOL-2010, it is not subject to any special protection [22-24]. This lizard has a blood response to altitude, in that lizards from $3600 \mathrm{~m}$ exhibit higher values of most blood traits than those from $2500 \mathrm{~m}$ However, lizards living at $4300 \mathrm{~m}$ have similar values to those from relatively $2500 \mathrm{~m}$ for hemoglobin concentration and erythrocyte size [18], (Figure 4). This was the first study that showed that the hematological response to hypoxia may differ between moderately high altitudes and extremely high altitudes, probably using morphophysiological adjustments we currently do not understand.
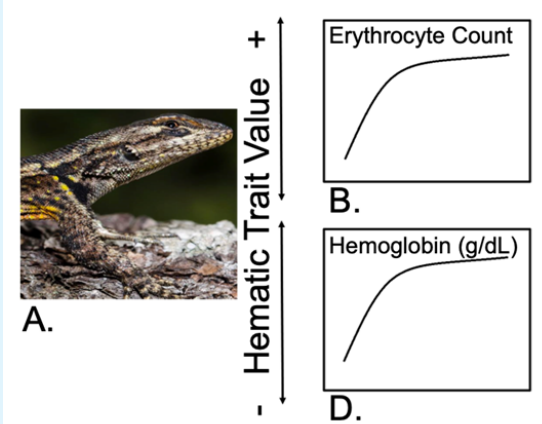

B.

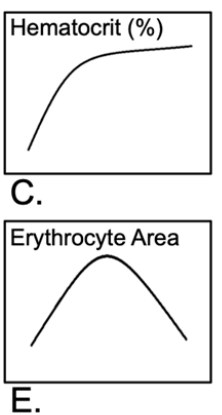

D.

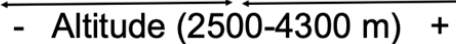

Figure 4: Blood values observed in Sceloporus grammicus, note the quadratic relationship between blood value and altitude. Source: Original creation based on data from González-Morales et al. [18].

Thermal set points in the genus Sceloporus appear to be evolutionarily conservative, although selected temperatures vary with altitude [31]. In our laboratory, we observed one individual of the species $S$ grammicus active at $5^{\circ} \mathrm{C}$ [27]. This within-species variability in thermal set points suggests that many species in the genus Sceloporus will be able to cope with global warming thanks to their wide altitudinal distributions. Lizards of the genus Sceloporus also appear to exhibit a blood response to hypoxia, which may also allow them to take advantage of high-altitude refuges from global warming. However, work on the blood response to hypoxia in other groups of reptiles is limited, with the exception of the lizard Phrynocephalus vlangalii, which shows responses similar to those observed in $S$. torquatus $[14,33]$. In addition, in our laboratory we studied the species Heloderma horridum with the aim of observing whether these organisms are capable of responding to hypoxia in a hematic manner [19].

H. horridum is a venomous lizard whose distribution is recorded from the Mexican state of Sonora to Guatemala. Its altitudinal distribution is reported from sea level to $1200 \mathrm{~m}$. It is a species considered "threatened" under Mexican law, due to the destruction of its habitat [19]. For this reason they are often kept and bred in captivity, although unfortunately many zoos or herpetariums are located outside their natural altitudinal range (for example, Africam Zafari in Puebla, at $2400 \mathrm{~m} 18^{\circ} 56^{\prime} 14^{\prime \prime}$ $\mathrm{N}$ and $98^{\circ} 08^{\prime} 12^{\prime \prime} \mathrm{W}$ ).

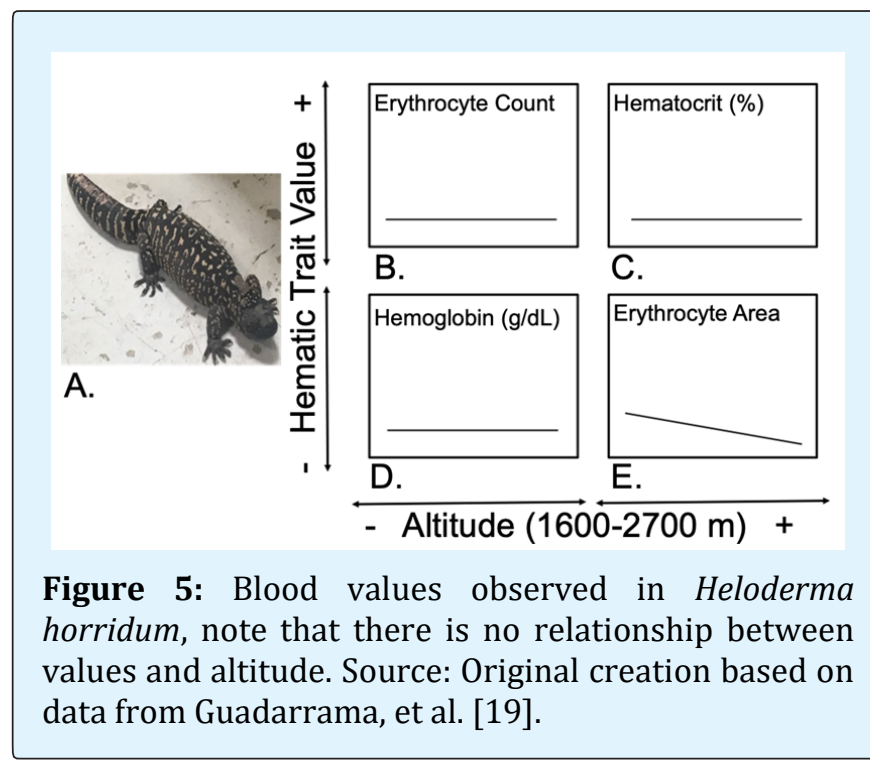

Previous work in our laboratory suggested that $H$. horridum does not show a blood response to changes in altitude [19], (Figure 5). However, these animals survive well in zoos at altitudes above their known altitudinal 


\section{International Journal of Zoology and Animal Biology}

range [34]. This ability may be explained, at least in part, by the biology of this species, which we know inhabits poorly oxygenated burrows for long periods (up to 62 days) [35]. In lizards, acclimation to hypoxia in the absence of a blood response may involve cardiac shunting [36]. These cardiac adjustments are typically defined by their direction, either as right-to-left (R-L) or left-to-right (L-R). A L-R shunt represents the recirculation of blood into the pulmonary circulation; this produces overoxygenation. Heloderma horridum may use a L-R shunt when faced with high-altitude environments $[37,38]$. Although $H$. horridum appears capable of dealing with the hypoxia present at high altitudes, from the sole study that exists of its thermal biology suggests the range of temperatures at which lizards of this species can be active is from 19.9 to $29.5^{\circ} \mathrm{C}$ [34]. If this active temperature range applies across the species, its distribution is likely to be limited to warm environments.

\section{Conclusion}

As average temperatures increase worldwide due to climate change, it seems logical to explore the idea that ectothermic species will be able to track their preferred temperatures by migrating to higher altitudes. Previous work on this hypothesis in saurians has focused primarily on their thermal biology. However, as we discuss here, hypoxia tolerance may also affect which lizard species can take advantage of high-altitude refuges from climate change $[14,18,19]$.

Comparative studies are necessary to understand how the blood response to altitude and other adaptations to hypoxia vary across reptiles and amphibians. Our laboratory has shown that there are morphological changes in gas exchange systems in salamanders of the genus Ambystoma in relation to altitude [39]. However, studies of morphological changes in the cardiovascular systems or in the metabolism of high or Low Mountain lizards are needed, which would allow us to know if there are other mechanisms through which ectotherms can cope with global warming. For example, changes in the size of the heart and lungs or even an increased micro capillary at the tissue level. Other metabolic changes may also occur; for example, individuals in hypoxic environments may show predominance of anaerobic muscle fibers, which would require less oxygen and glucose for their daily activities and could also reduce oxidative stress and therefore increase longevity. All these questions remain to be explored in the diverse groups of reptiles.

\section{Acknowledgement}

We would like to thank the Secretariat of Research and Advanced Studies of the Autonomous University of the State of Mexico for its financial support for carrying out the studies discussed here, as well as the National Council of Science and Technology.

\section{References}

1. Petit JR, Jouzel J, Raynaud D, Barkov NI, Barnola JM, et al. (1999) Climate and atmospheric history of the past 420,000 years from the Vostok ice core, Antarctica. Nature 399: 429-436.

2. Barry RG, Chorley RJ (2003) Atmosphere, Weather, and Climate. $1^{\text {st }}$ (Edn.), Routledge Taylor \& Francis Group, New York, USA.

3. Brohan P, Kennedy JJ, Harris I, Tett SFB, Jones PD (2006) Uncertainty estimates in regional and global observed temperature changes: a new dataset from 1850. J Geophy Res 111: D12106.

4. Caballero M, Lozano S, Ortega B (2007) Greenhouse effect, global warming and climate change: a perspective from the earth sciences. Rev Dig Univ 8(10): 2-12.

5. IPCC (2018) Summary for Policymakers. In: Global Warming of $1.5^{\circ} \mathrm{C}$. An IPCC Special Report on the impacts of global warming of $1.5^{\circ} \mathrm{C}$ above preindustrial levels and related global greenhouse gas emission pathways, in the context of strengthening the global response to the threat of climate change, sustainable development, and efforts to eradicate poverty. Masson Delmotte V, Zhai P, Pörtner HO, Roberts D, Skea J, Shukla PR, Pirani A, Moufouma Okia W, Péan C, Pidcock R, Connors S, Matthews JBR, Chen Y, Zhou X, Gomis MI, Lonnoy E, Maycock T, Tignor M, Waterfield T, et al. (Eds.), In Press.

6. Sinervo B, Méndez de la Cruz FR, Miles DB, Heulin B, Bastiaans E, et al. (2010) Erosion of lizard diversity by climate change and altered niches. Science 328: 894-899.

7. Sinervo B, Miles DB, Wu Y, Mendez de la Cruz FR, Kirchhofet S, et al. (2018) Climate change, thermal niches, extinction risk and maternal-effect rescue of toad-headed lizards, Phrynocephalus, in thermal extremes of the Arabian Peninsula to the QinghaiTibetan Plateau. Integr Zool 13(4): 450-470. 


\section{International Journal of Zoology and Animal Biology}

8. Pough HF (1980) The adventages of ectothermy for tetrapods. Am Nat 115: 92-112.

9. Pough FH, Andrews RM, Cadle JE, Crump ML, Savitzky AH, et al. (2001) Herpetology. Ryu T, et al. (Eds.), Prentice Hall, New Jersey.

10. Snyder GK, Weathers WW (1997) Activity and oxygen consumption during hypoxic exposure in high altitude and lowland sceloporine lizards. J Comp Physiol 117: 291-301.

11. Bouverot P (1985) Adaptation to altitude-hypoxia in Vertebrates. Berlin, Springer Verlag.

12. Ruiz G, Rosenmann M, Veloso A (1983) Respiratory and hematological adaptation to high altitude in Telmantobius frog from Chilean Andes. Comp Biochem Physiol A 76: 109-114.

13. Ruiz G, Rosenmann M, Veloso A (1989) Altitudinal distribution and blood values in the toad, Bufo spinulosus Wiegmann. Comp Biochem Physiol A 94(4): 643-646.

14. González Morales JC, Quintana E, Díaz Albiter EH, Guevara-Fiore P, Fajardo V (2015) Is the erythrocyte size a strategy to avoid hypoxia in Wiegmann's Torquate Lizards (Sceloporus torquatus)? Field evidence. Can J Zool 93: 377-382.

15. Monge C, Leon Velarde F (1991) Physiological adaptation to high altitude: oxygen transport in mammals and birds. Physiol Rev 71(4): 1135-1172.

16. Schulte PM (2015) The effects of temperature on aerobic metabolism: towards a mechanistic understanding of the responses of ectotherms to a changing environment. J Exp Biol 218(12): 18561866.

17. Storz JF, Moriyama H (2008) Mechanims of hemoglobin adaptation to high altitude hypoxia. High Alt Med Biol 9(2): 148-157.

18. González Morales JC, Beamonte Barrientos R, Bastiaans E, Guevara-Fiore P, Quintana E, et al. (2017) A mountain or a plateau? Hematological traits vary non linear with altitude in Highland lizard. Physiol Biochem Zool 90(6): 638-645.

19. Guadarrama S, Dominguez Vera H, Diaz Albiter HM, Quijano A, Bastiaans E, et al. (2019) Hypoxia by altitude and welfare of captive Beaded lizards
(Heloderma horridum) in Mexico: Hematological approaches. J Appl A Well Sci pp: 1-9.

20. Feria Ortiz M, Nieto Montes de Oca A, Salgado Ugarte I (2001) Diet and reproductive biology of the viviparus lizard Sceloporus torquatus torquatus (Squamata: Phrynosomatidae). J Herpetol 35(1): 104-112.

21. Flores Villela OA, Gerez P (1994) Biodiversidad y conservación en México: vertebrados, vegetación y uso de suelo. CONABIO-UNAM, México.

22. Uribe Pena ZA, Ramirez Bautista A, Casas Andreu G (1999) Anfibios y reptiles de las serranías del Distrito Federal, México. Instituto de Biología, UNAM, México DF. 119.

23. Méndez de la Cruz FR, Gutiérrez Mayén MG (1991) Changing the physical robustness of sceloporus torquatus (sauria: iguanidae) and its implications on the season of reproduction. Acta Zool Mex 46: 1-12.

24. Wheathers W, White W (1972) Hematological observations on populations of the lizard Sceloporus occidentalis from sea level and altitude. Herpetologica 28(2): 172-175.

25. Rivera Rea J, Gonzalez Morales JC, Bastiaans E, Fajardo V (2018) Sceloporus Torquatus (Torquate Lizard). Selected body temperature. Herp Rev 49(3): 6.

26. Gonzalez Morales JC, Rivera Rea J, Moreno Rueda G, Bastiaans E, Diaz de la VegaPerez AH, et al. (2019) To be small and dark is advantageous for gaining heat in highland mezquite lizards. J Zool Can In press.

27. Adolph SC, Porter WP (1993) Temperature, activity, and lizard life histories. American Naturalist 142(2): 273-295.

28. Ortega Z, Mencia A, Perez Mellado V (2016) Adaptative seasonal shifts in the thermal preferences of the lizard Iberolacerta galani (Squamata: Lacertidae). J Therm Biol 62: 1-6.

29. Crowley SR (1985) Thermal sensitivity of sprintrunning in the lizard Sceloporus undulatus: support for a conservative view of thermal physiology. Oecologia 66(2): 219-225.

30. Andrews RM (1998) Geographic variation in field body temperature of Sceloporus lizards. J Therm Biol 23(6): 329-334. 


\section{International Journal of Zoology and Animal Biology}

31. Lemos Espinal JA, Ballinger RE (1995) Comparative thermal ecology of the high-altitude lizard Sceloporus grammicus on the eastern slope of the Iztaccihuatl Volcano, Puebla, Mexico. Can J Zool 73: 2184-2191.

32. He J, Xiu M, Tang X, Yue F, Wang N, et al. (2013) The different mechanisms of hypoxic acclimatization and adaptation in lizard Phrynocephalus vlangalii living on Quinghai-Tibet Plateau. J Exp Zool 319(3): 117-123.

33. Beck D (2006) Biology of Gila monster and beaded lizards. California, University of California Press. USA.

34. Ariano Sanchez D, Salazar G (2015) Spatial ecology of the endangered Guatemalan beaded lizard Heloderma charlesbogerti (Sauria: Helodermatidae), in a tropical dry forest of the Motagua Valley, Guatemala. Mesoamerican Herpetol 2(1): 64-74.
35. Hicks JW (2002) The physiological and evolutionary significance of cardiovascular shunting patterns in reptiles. Am Physiol Soc 17: 241-245.

36. Birchard GF, Kilgore DL, Bogss DF (1984) Respiratory gas concentrations and temperatures within the burrows of three species of burrow nesting birds. The Wilson Bulletin 96: 451-456.

37. Hillman SS (2009) Ecological and environmental physiology of amphibians. New York, NY: Oxford University Press.

38. Arredondo J, Gonzalez Morales JC, Rodriguez Antolin J, Bastiaans E, Monroy Vilchis 0, et al. (2017) Histological Characteristics of gills and dorsal skin in Ambystoma leorae and Ambystoma rivulare: Morphological changes for living at high altitude. Int J Morphol 35(4): 1590-1596. 